\title{
VIOLÊNCIA DE GÊNERO E ASSÉDIO SEXUAL NA UNIVERSIDADE
}

\author{
Rebeca Hennemann Vergara de Souza (UESPI) ${ }^{1}$ \\ Maria Paula da Silva França (UFPI) \\ Camila Macêdo Pereira ${ }^{3}$
}

\section{RESUMO}

Este trabalho pretende discutir uma manifestação específica da violência de gênero, o assédio sexual, especialmente aquele praticado na universidade, a partir de dados de duas pesquisas realizadas em uma instituição pública de ensino superior no Piauí. Os resultados apontam que o assédio sexual faz parte da vivência universitária das mulheres, embora, dada a estrutura das relações de poder entre os gêneros, identifique-se certa dificuldade em nomear e identificar prontamente a violência, muitas vezes tida como brincadeira ou piada de caráter sexual. Ainda assim, as mulheres relatam constrangimento e repulsa diante das situações de assédio. As mulheres também demonstram receio em falar sobre o assunto e, especialmente em uma das pesquisas, oferecem respostas informais distintas das que apontaram no questionário. $O$ assédio sexual se objetiva no dia a dia, na sala de aula ou nos corredores, e através de mediação tecnológica e produz efeitos no desempenho e nas oportunidades escolares das discentes. Lidos à luz das estatísticas nacionais sobre violência de gênero, os dados nos indicam a necessidade não apenas de estudos aprofundados sobre o tema, como também de políticas institucionais de acolhimento e enfrentamento.

Palavras-Chave: Violência sexual. Ensino Superior. Relações de poder.

\section{INTRODUÇÃO}

A despeito destas lutas centenárias e dos avanços em termos de direitos, as mulheres ainda sofrem uma série de violências relacionadas a seus atributos sociais como mulheres, bem como à posição mais geral da mulher na sociedade. Para Heleieth Saffioti (2015, p.18), a violência é uma "ruptura de qualquer forma de integridade da vítima: integridade física, integridade psíquica, integridade moral", mesmo quando situam-se

1Mestre em Sociologia. Universidade Estadual do Piauí. E-mail: sr.keuner@gmail.com 2Licenciada em Ciências Sociais . Universidade Federal do Piauí. E-mail: paulamaria.fs@outlook.com 3Licenciada em História. Sem vinculação institucional. E-mail: camilamacedo9@gmail.com 
fora do diretamente observável, e produz efeitos físicos, psíquicos e sociais. Muitas violências que se praticadas com outros seres humanos seriam consideradas imediatamente reconhecidas como tais, quando praticadas contra mulheres, são naturalizadas (BUNCH, 1995; BARSTED, 2016). Desde as últimas décadas do século XX, o termo violência de gênero tem sido utilizado para identificar e descrever um amplo rol de ações praticadas, especialmente, contra as mulheres em função de sua condição de gênero.

Neste trabalho, pretendemos discutir uma manifestação específica da violência de gênero, o assédio sexual, especialmente aquele praticado na universidade. Entendemos que, como violência de gênero, o assédio sexual expressa relações de poder entre homens e mulheres no meio acadêmico.

\section{METODOLOGIA}

O presente trabalho discute os dados de duas pesquisas realizadas em uma universidade pública estadual, no estado do Piauí, sobre assédio sexual. A primeira pesquisa tinha por objetivo realizar um diagnóstico das condições de vida das mulheres trabalhadoras e estudantes e foi realizada entre os anos de 2016 e 2017, em um campus do interior do Estado. A segunda pesquisa, realizada em 2018, resultou em um trabalho de conclusão de curso em Ciências Sociais e objetivou investigar as práticas de assédio sexual como parte das relações de poder estabelecidas entre professores e alunas de uma universidade pública na cidade de Teresina - Piauí.

As condições de vida das mulheres foram analisadas em três eixos, sendo um deles sobre segurança, integridade e bem-estar das mulheres, focando nas situações de violência relacionadas direta ou indiretamente à vida acadêmica. A pesquisa foi realizada através da aplicação de um questionário semiestruturado a 139 mulheres que trabalham 
ou estudam em um campus do interior do estado do Piauí (professoras, técnicas, funcionárias terceirizadas, trabalhadoras autônomas e estudantes).

Já a segunda pesquisa foi realizada em um campus em Teresina e foi realizada através de entrevista em profundidade com seis mulheres, quatro das quais se apresentaram espontaneamente para participação na pesquisa e outras duas foram selecionadas aleatoriamente. A entrevista abordou sua percepção geral sobre a vida acadêmica e as narrativas de assédio.

\section{RELAÇÕES DE GÊNERO E ASSÉDIO SEXUAL NA UNIVERSIDADE}

Para Pierre Bourdieu (2012), a escola é uma das instâncias principais de elaboração e imposição dos princípios da dominação masculina. A universidade, como um espaço social, também é estruturado por e estruturante de relações de poder, no sentido dado por Michel Foucault (1979). As relações entre homens e mulheres podem ser compreendidas como relações desta natureza na medida em que é possível identificar uma série de mecanismos disciplinares que atuam na produção de certos efeitos sociais sobre os corpos individuais e coletivo, regulando a própria relação de ensino aprendizagem e não apenas aprofundando as assimetrias de gênero, como também criando um olhar vigilante sobre as alunas, docentes e funcionárias.

As relações de poder que regulam os gêneros podem exercer-se através de diferentes dispositivos, dentre eles, as práticas masculinas de natureza sexual dirigidas às mulheres em um contexto de hierarquia institucional (PAMPLONA FILHO, 2001), nomeadas genericamente de assédio sexual. Para o autor, o assédio é "toda conduta de natureza sexual não desejada, que embora repelida pelo destinatário, é continuadamente reiterada, cercando-Ihe a liberdade". (PAMPLONA FILHO, 2001, p.4). Essa concepção ampliada de assédio é adotada por Daniele Janssen (2013) para propor uma interpretação 
do assédio sexual na relação entre professor e aluna, na qual, no lugar da ameça ao vínculo empregatício, as ameaças são feitas ao desempenho escolar.

Como problema de gênero (FUKUDA, 2012), o assédio sexual é revelador das relações de poder entre os homens e mulheres envolvidos, notadamente as hierarquias e constrangimentos socialmente legitimadas, cujas formas e abordagens são variáveis. $\mathrm{Na}$ maioria dos casos, o sujeito ativo do comportamento configurador do assédio sexual é o homem, e são afetadas, predominantemente, as mulheres, embora possa ser o contrário, mas em proporção muito menor (PAMPLONA FILHO, 2005).

O assédio sexual pode ser caracterizado através de diversos atos, desde insinuações de caráter sexual mais ou menos explícito até ameaças físicas ou verbais a fim de obter favores sexuais (PAMPLONA FILHO, 2001; JANSSEN, 2013). Dentre estes atos, estão inclusas piadas, comentários e convites insistentes que importunem ou causem constrangimento à vítima. A amplitude dos atos de assédio sexual está relacionada à própria concepção de natureza da sexualidade feminina, cuja sexualidade é considerada corporalmente difusa (SAFFIOTI, 2015). Entretanto, há áreas corporais e comportamentos que são mais facilmente identificados como erotizáveis, sendo portanto mais facilmente reconhecidos como objetos de assédio, enquanto outros integram a grande área cinzenta da interpretação.

Em uma pesquisa sobre assédio realizada em uma universidade estadual no Paraná, Sá, Folriani e Rampazo (2017), apontaram que a hierarquização de posições na universidade se soma à hierarquização de gênero, tornando mais difícil para as discentes reagirem ao assédio.

Cerca de $50 \%$ das entrevistadas manifestaram explicitamente que forneceriam uma resposta suavizada ou negativa por medo de serem identificadas e retaliadas pelos agressores: "acontece, mas coloca ai que não". De um lado, compreende-se que as garantias de sigilo dos dados são limitadas em uma comunidade que, tomando de empréstimo o termo proposto por Mendras (1976) para caracterizar as comunidades 
camponesas, caracteriza-se como de interconhecimento, os riscos de identificação e mesmo de saber-se que falou-se sobre o assunto são grandes. De outro lado, a própria dinâmica da violência contra a mulher dificulta sua identificação e qualificação como tal. Nesse sentido, os dados numéricos sobre violência aqui apresentados necessitam ser relativizados e lidos de forma qualitativa.

A pesquisa realizada em Campo Maior entrevistou 139 mulheres, entre 21 e 67 anos que trabalhavam ou estudavam no Campus. O perfil predominante das participantes foi composto por mulheres solteiras $(70 \%)$, heterossexuais $(95,7 \%)$, sem filhos $(70 \%)$, autoidentificadas como pardas $(63,2 \%)$ ou negras $(19,7 \%)$ e católicas $(71,9 \%)$ e com idade média de 27 anos. Este perfil deve, contudo ser relativizado quando se considera a composição das entrevistadas quanto ao seu vínculo com o Campus: 80,3\% são alunas, as funcionárias correspondem a $13,7 \%$ de total de respondentes e as professoras, a $6 \%$. $\mathrm{A}$ maioria das entrevistadas (72\%) exercem algum tipo atividade remunerada ou recebem algum tipo de auxílio, inclusive auxílios de assistência estudantil ofertados pela universidade; $18 \%$ dependem da renda de outras pessoas ou $10 \%$ não responderam.

O segundo estudo foi realizado com seis mulheres jovens, entre 22 e 35 anos, estudantes de curso de graduação, todas autoidentificadas como heterossexuais e solteiras. Em relação à identificação étnico-racial, quatro mulheres se autodeclararam negras ou pardas; uma se percebe como branca e a outra não soube responder. Das seis, três trabalham em atividades informais e as outras três não possuem atividades remuneradas. Duas entrevistadas já participaram de programas de assistência social ou de iniciação científica na universidade e as outras quatro, não.

O campus do interior é uma unidade pequena, composta por um bloco único para salas de aula, laboratório e setor administrativo para o período regular e por um número reduzido de alunos e professores quando comparado a outras unidades da mesma instituição. Este cenário de interconhecimento produz uma relativa sensação de segurança entre as mulheres que estudam e trabalham no campus. Entretanto, três em 
cada dez mulheres sentem-se inseguras no campus, especialmente funcionárias e alunas.

Entre os fatores elencados para a insegurança e medo estão a vulnerabilidade da segurança (39\%); fatores ligados à estrutura do campus como o isolamento e baixa iluminação (23\%); o sentimento de insegurança generalizada (16\%); o assédio sexual (10\%); e a violência já presenciada dentro do campus (6\%). Outras 6\% não justificaram a razão de sua insegurança.

Quando questionadas sobre o assédio sexual, a maioria das respondentes (93\%) disseram nunca ter presenciado casos dentro do espaço acadêmico. Das $7 \%$ que presenciaram situações de assédio, 50\% citaram comentários e cantadas ofensivas de cunho sexual; 37,5\% a abordagem de natureza sexual não desejada ou insistência inoportuna por parte de colegas de sala ou de trabalho; e 12,5\%, a invenção de boatos sobre a sexualidade.

Entretanto, quando questionadas sobre a vivência de situações específicas, que caracterizam o assédio sexual, $23 \%$ das entrevistadas já escutaram comentários e piadinhas sobre seu corpo; $1 \%$ declarou já ter recebido propostas para trocar favores sexuais por algum beneficio; $14,2 \%$ já se sentiram incomodadas com as atitudes de homens dentro da universidade; $59,8 \%$ com o olhar de um homem dirigido a elas; e $32 \%$ já se retiraram de um local pela presença de um homem.

A dificuldade em identificar e nomear como violência práticas de assédio sexual também foi relevada entre as seis entrevistadas. Embora no planejamento da pesquisa, tenhamos optado por trabalhar com a categoria assédio sexual, em sentido amplo, as entrevistadas recorreram a outras duas categorias como constrangimento e abuso. Neste sentido, procuramos compreender o sentido que as entrevistadas conferem às situações de violência que sofreram, independente da tipificação legal. De forma geral, percebe-se que há certa dificuldade em nomear os acontecimentos e esta oscilação semântica vai ao encontro da dificuldade em caracterizar o assédio sexual diante da legitimação social dos comportamentos nos quais ele se objetifica (FUKUDA, 2012). Parece haver, hipótese a ser 
investigada de forma mais aprofundada em estudos posteriores, um continnum que estabelece gradações na violência, do constrangimento ao assédio, passando pelo abuso.

Nas duas pesquisas, prevalecem as piadas de conteúdo sexual, olhares constrangedores, comentários sobre o corpo ou roupa, perguntas íntimas e pessoais e convites para atividades fora da universidade, constituindo o que Pamplona Filho (2001) designa como condutas não desejadas e desagradáveis para a receptora, as quais são umas das características do assédio sexual.

A dificuldade de identificar e nomear a violência também se traduz na percepção, pelo menos inicial, das práticas como brincadeiras, como verificamos no extrato de entrevista acima. Sá, Folriani e Rampazo (2017) também identificaram que brincadeiras e piadas são formas comuns de assédio no ambiente universitário que dificultam a nomeação das experiências constrangedoras como assédio.

A designação do assédio como brincadeira, entretanto, deve ser compreendida não do ponto de vista exclusivo das mulheres vítimas destas formas de violência, mas da sutileza e da conivência social com certos comportamentos de natureza machista. A dificuldade das entrevistadas em chamar de assédio sexual ou outra nomenclatura que explicite o caráter violento é menos uma não percepção da violência e mais um reflexo da própria natureza do assédio. O fato do assédio, por vezes, ser praticado tom de brincadeira, faz com que as mulheres sintam dificuldades em relatá-lo como tal. Frases como "meio assim", "conversa”, "brincadeira" demonstram a dúvida em utilizar a palavra assédio para denominar o ocorrido. Essa dúvida pode acentuar-se ainda mais quando o assédio acontece em sala de aula, com testemunhas.

Na pesquisa sobre condições de vida de mulheres, verificou-se que há casos de mulheres testemunhas, especialmente nos casos de violência física, não sendo identificadas testemunhas de assédio sexual. Já na segunda pesquisa, Amanda, Dama da Noite e Violeta relataram situações em que o assédio ocorreu na presença de outras testemunhas, especificamente outros homens. 
Sá, Floriani e Rampazo (2017, p.25-26) também identificaram a presença e co participação de testemunhas nos atos de assédio. Segundo os autores, "piadas, brincadeiras e cantadas de cunho sexual são comumente ouvidas nos corredores das universidades [...] na maioria das vezes de forma descontraída, em que todos ao redor se divertem e acham normal a situação". A presença de testemunhas parece ser essencial para a normalização do assédio como brincadeira, dificultando sua classificação como ato violento.

A segunda pesquisa também identificou contato físico não consentido entre professores e alunas, como pegar no cabelo, abraços, beijos, toque em diferentes partes do corpo. Quando o assédio é realizado através de situações que envolvem contato físico direto, as entrevistadas demonstram maior facilidade em identificá-las como violência, independente da sua posição no espectro.

Reiteradamente, as entrevistadas reafirmam sua não concordância com as situações vividas, dizem que nunca gostaram, que disseram não, revidaram, se afastaram, repudiaram. Na primeira pesquisa, $32 \%$ já se retiraram de um local pela presença de um homem a fim de evitar a situação de assédio. Na segunda pesquisa, as discentes relatam que revidaram, não responderam e, no limite, abandonaram projetos e atividades para não encontrar o assediador.

Informalmente, as entrevistadas citaram casos de seu conhecimento envolvendo professores e alunas, funcionários e alunas e funcionários e alunas. A segunda pesquisa focou na relação professor-aluna e por isso casos envolvendo funcionários não foram investigados. Nesta pesquisa, seis mulheres vítimas de assédio por parte de professores foram entrevistadas e todas possuíam uma história estruturalmente semelhante quanto ao tempo, local do assédio e forma do assédio. 
Na segunda pesquisa, as situações de assédio e abuso sexual, em sua maioria, ocorreram nos dois anos iniciais dos cursos, indicando a existência de um padrão de ação dos docentes e uma preferência por abordar as mulheres no início da sua vida acadêmica quando há uma maior vulnerabilidade social, falta de maturidade e de vivência na universidade. Ao ingressar na universidade e se deparar diretamente com o assédio, pode-se ocasionar surpresa e quebra de expectativa por não esperar que atitudes assim possam vir de professores, que em algum momento, foram admirados por essas mulheres e, em um lugar social que guarda a expectativa de segurança.

Alguns casos duraram um período relativamente curto de tempo, como um semestre. Outros, entretanto, perduraram por mais de um semestre, pois muitos professores retornavam às salas de aulas com outras disciplinas, dando continuidade aos assédios. Maria, Clara e Amanda vivenciaram situações de assédio por vários meses, sendo que a última, até o dia da entrevista, confirmou que as situações ainda aconteciam. $\mathrm{O}$ assédio, entretanto, pode ser praticado através de diferentes meios, seja no mesmo período de tempo, seja em momentos distintos, descontinuados, indicando a plasticidade do exercício do poder. Por exemplo, comentários desagradáveis podem evoluir para contatos físicos não autorizados; contatos ocasionais na universidade, para convites para sair e contatos através de redes sociais, fora do contexto acadêmico; contatos físicos esporádicos e sutis, para atitudes de perseguição on line e insistência para encontros.

Embora a pesquisa não tenha focado nas práticas de perseguição virtual ou eletrônica, há indícios de sua forte presença nas situações vividas pelas universitárias, pois as jovens relatam que as redes sociais, como WhatsApp, e as mensagens de texto foram utilizadas como forma de prolongar o assédio no tempo e no espaço, para fora da sala de aula e dos corredores da universidade. 
Outro elemento característico do assédio sexual no ambiente acadêmico, é o agressor valer-se de sua condição de ascendência, baseada em uma relação de domínio, influência e respeito (JANSSEN, 2013) para afetar ou ameaçar afetar negativamente o desenvolvimento acadêmico da aluna.

O abuso da autoridade docente, no contexto mais amplo de situações de assédio sexual, caracterizam uma tentativa de chantagem (PAMPLONA FILHO, 2001), na qual o professor utilizada de sua posição de ascendência seja para produzir, simultaneamente, uma espécie de punição por não ter obtido o resultado esperado com as investidas anteriores e produzir uma tensão subjetiva, procurando construir uma situação da qual não há escapatória do exercício do poder masculino, seja cedendo às investidas, seja sendo prejudicada. Nesse sentido, situações corriqueiras da vida acadêmica são transformadas em oportunidades para prolongar o assédio sexual, agora convertido em assédio moral que atua diretamente sobre o desempenho das estudantes.

A despeito do sentimento de perseguição e constrangimento, as entrevistadas adotaram medidas individuais diante do assédio sexual, como abandonar disciplinas ministradas pelo professor e não frequentar os mesmos espaços. Na primeira pesquisa, embora a maioria das participantes (77\%) tenha declarado confiar na universidade para denunciar algum caso de violência que sofresse ou testemunhasse na instituição, apenas uma pessoa, informalmente, relatou ter levado o caso à administração do campus e não obteve solução para o caso, pelo contrário, sua percepção é de que o agressor foi protegido. Já $23 \%$ das entrevistadas declararam não confiar na instituição para apresentar denúncia, o mesmo ocorrendo com as seis entrevistadas na segunda pesquisa, cujos casos não chegaram a nenhuma instância institucional.

Para compreender a ausência de denúncias e o desinteresse institucional por (re)conhecer esta realidade, é necessário discutir como a naturalização dos processos socioculturais de discriminação contra a mulher legitima a "superioridade" dos homens (SAFIOTTI, 1987, p.11). A ausência de denúncias é reveladora da existência de 
GONGRESSO CIENCIAESOCIEDADE

desconfiança quanto à capacidade institucional de resposta aos casos de assédio e violência. A dificuldade em reconhecer a conduta sendo agressiva e até se perceber como vítima, faz com que muitas mulheres não queiram denunciar os casos de assédio sexual. Além disso, como afirma Fukuda (2012), especialmente em casos de crimes sexuais, a conduta do agressor é minimizada em detrimento das vítimas, cujas atitudes são colocadas sob suspeição e julgamento, desencorajando as denúncias.

\section{CONSIDERAÇÕES FINAIS}

Neste trabalho, discutimos o assédio sexual praticado contra mulheres, na universidade, como uma forma de violência que expressa relações de poder entre gêneros. A despeito de certa dificuldade em identificar e nomear a violência, as mulheres qualificam as situações vividas como constrangedoras e indevidas, manifestando sentirem-se inclusive perseguidas.

Há uma experiência histórica acumulada pelas mulheres que se traduz em um senso prático sobre a ineficácia das denúncias, as quais geralmente produzem mais sofrimento para elas que ações contra o agressor, e em certa desconfiança institucional. Lidos à luz das estatísticas nacionais sobre violência de gênero, estes dados nos indicam a necessidade não apenas de estudos aprofundados sobre o tema, como também de políticas institucionais de acolhimento e enfrentamento.

\section{REFERÊNCIAS}

BARSTED, L. L. O feminismo e o enfrentamento da violência contra as mulheres no Brasil. In: SARDENBERG, C. M.; TAVARES, Márcia S. (orgs). Violência de gênero contra mulheres: suas diferentes faces e estratégias de enfrentamento e monitoramento. Salvador: EDUFBA, 2016. p.17-40. 


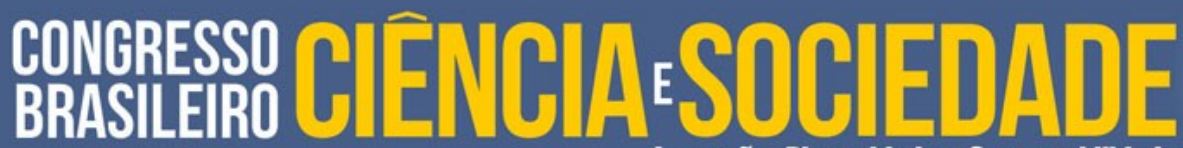 \\ Inovação, Diversidlatie e Sustentahililitatie}

BLAY, E. A. Assassinato de mulheres e direitos humanos. São Paulo: USP/PPG Sociologia: ed.34, 2008.

BOURDIEU, P. A dominação masculina. 11 ed. Rio de Janeiro: Bertrand Brasil, 2012.

BUNCH, C. Los derechos de la mujer como derechos humanos: hacia una revisión de los derechos humanos. In: BUNCH, Charlotte; CARRILLO, Roxanna. Violencia de genero: um problema de desarrollo y derechos humanos. New Brunswick: Centro de Liderazgo Global de la Mujer, 1995. p.3-22.

FOUCAULT, M. Microfísica do poder. Rio de Janeiro: Graal, 1979.

FUKUDA, R.F. Assédio sexual: uma releitura a partir das relações de gênero. Simbiótica, n.1., p.1-17, junho-2012. Disponível em:

$<$ http://periodicos.ufes.br/simbiotica/article/view/4512/3516 $>$.

JANSSEN, D. $\mathbf{O}$ assédio sexual? Professor e aluno. Disponível em:

http://phmp.com.br/artigos-epublicacoes/artigo/o-assedio-sexual-professor-e-aluno/. Acesso em: 23 mai 2019.

MENDRAS, H. Sociétés paysannes. Paris: A. Colin, 1976.

PAMPLONA FILHO, R. Assédio sexual: questões conceituais. Revista de Direito do Trabalho, v. 27, n. 103, p 182-199, jul. /set. 2001. Disponível em:

www.andt.org.br/f/20131533_ANDT_artigo_assedio_Rodolfo.pdf. Acesso em: 23 mai 2019.

SÁ, B.S.; FOLRIANI, M.D.; RAMPAZO, A.V. Assédio sexual: o poder do macho na universidade. Estudos de administração e sociedade, v.3, n.2, p.22-31, 2017. Disponível em: http://periodicos.uff.br/revistaeas/article/view/27415. Acesso em 23 mai 2019.

SAFFIOTI, H. Gênero, patriarcado, violência. São Paulo: Expressão Popular: Perseu Abramo, 2015. 